\title{
Undescended testes: a consensus on management
}

\author{
E Martin Ritzén \\ Department of Woman and Child Health, Karolinska Institutet, S-171 76 Stockholm, Sweden \\ (Correspondence should be addressed to E M Ritzén; Email: martin.ritzen@ki.se)
}

\begin{abstract}
The mode of treatment best for undescended testes is controversial, and local traditions often override knowledge gained from randomized controlled studies. In order to reach a consensus within the Nordic countries on the current state-of-the-art of treatment, a group of specialists in testicular physiology, paediatric surgery/urology, endocrinology, andrology, pathology and anaesthesiology from all the Nordic countries met for 2 days. Before the meeting, reviews of the literature had been prepared by the participants. Judging from published meta-analyses, hormonal treatment has low efficacy. Although $15-20 \%$ of retained testes descend during hormonal treatment, one-fifth of these re-ascend later on. Also, treatment with human chorionic gonadotropin (hCG) may be harmful to future spermatogenesis through increased apoptosis of germ cells. Orchiopexy, on the contrary, results in about 95\% anatomical success, with a low (about 1\%) risk of complications. The optimal time for orchiopexy has also been debated. However, a recent randomized controlled study shows that surgery at 9 months of age is followed by a better post-operative growth of the testes than surgery at 3 years, which supports previous arguments for early surgery. The unanimous conclusion of the group was that surgery is generally the preferred mode of treatment, rather than hCG or GnRH treatments. Orchiopexy should be performed between 6 and 12 months of age, or soon after diagnosis, if that occurs later. If a testis is found to be undescended at any age after 6 months, the patient should be referred for surgery. Referral should be to paediatric rather than general surgeons/urologists if the boy is less than 1 year old, if he has bilateral or non-palpable testes, or if he has got relapse of cryptorchidism.
\end{abstract}

European Journal of Endocrinology 159 S87-S90

\section{Introduction}

Incomplete descent of one or both testicles is the most common birth anomaly in boys, affecting $2-8 \%$ (1). Thus, it is not surprising that this condition has attracted many clinical scientists over the years. But when it comes to the final end point of treatment, the function of the testis in the adult man, the publications are few. A PubMed search on 'human cryptorchidism and therapy' produces 2949 hits for the period 19652007. It seems that all these publications would guide the clinician to the optimal management of undescended testes (UDT). But clinical practice should ideally be based on the results of randomized controlled trials. If this criterion is added to the PubMed search and publications on specific methods for surgery or anaesthesiology are excluded, only 12 publications remain. Out of these, a mere three report more than 1 year of follow-up and none of them report follow-up until adulthood.

This paper was presented at the 5th Ferring International Paediatric Endocrinology Symposium, Baveno, Italy (2008). Ferring Pharmaceuticals has supported the publication of these proceedings.
In the absence of the ideal randomized controlled studies from infancy to adulthood, we still have to make decisions about the management of UDT. Local therapeutic traditions have in many cases overtaken the objective evaluation of available knowledge. Important new pieces of information have lately emerged on pros and cons of different treatment modalities, as well as optimal age for treatment. Therefore, a group of experts from the Nordic countries decided to summarize the available information from literature and then get together for a 2-day consensus meeting on the management of UDT. A consensus was reached and a statement as well as a number of reviews on relevant literature was published (1-6). This chapter is a summary of these articles.

\section{Why should we bother about UDT?}

Testosterone production is at least partly maintained even in a retained testis. Boys with bilateral cryptorchidism will go through normal male puberty. There is, however, convincing evidence that a testis situated in the abdomen or in the inguinal canal is unable to produce spermatozoa (summarized in (1)), and that 
spermatogenesis is improved if such a testis can be placed in the scrotum (7). The small difference in temperature $\left(2-3{ }^{\circ} \mathrm{C}\right)$ between the abdomen and the scrotum is detrimental to normal spermatogenesis.

Unilateral UDT is four times more common than bilateral. The natural course of unilateral UDT (without treatment) is largely unknown, since treatment has been the standard of care for a long time. In unilateral UDT, the descended, scrotal, testis might compensate for the poor sperm production in the retained testis. However, all studies of adult men with unilateral UDT show that the sperm count is lower than normal, even if conventional orchiopexy during childhood has been successful. On the other hand, fertility in this group of patients, defined as ever having fathered a child, may still approach that of the background population $(8,9)$. We should, however, strive for optimization of spermatogenesis in every boy born with UDT.

There has been a long-standing debate over whether the increased incidence of malignancies in retained testes can be alleviated by bringing it into the scrotum. This has recently been shown to be the case; boys whose testes had been placed in the scrotum before 13 years of age showed a significantly reduced risk compared to those operated after that age (10).

The conclusion of the consensus group was that efforts should be made to bring all retained testes into the scrotum.

\section{How should the boy with UDT be treated?}

Over the years, two principally different methods have been advocated; either hormonal treatment with human chorionic gonadotropin (hCG) or gonadotropin-releasing hormone, or primary surgery. There are no randomized controlled studies comparing the two approaches, but numerous reports on the results of one or the other. In the absence of solid proof, local traditions have become prevalent. Thus, in the USA, surgery has generally been preferred as the method of choice, while in many parts of Europe hormonal therapy has been preferred as the first treatment. In case the latter is unsuccessful in bringing the testis into the scrotum, the patient is referred to surgery.

Individual reports give very variable success rates after hormonal therapy, from 8 to $60 \%$ anatomical success (defined as scrotal position, without signs of atrophy) (5). Most authors blame the widely varying results on a varying degree of inclusion of retractile testes in the study groups. Three meta-analyses of available randomized controlled studies were found (11-13). They all agree on an overall efficacy of around $20 \%$, which upon follow-up is decreased to about $15 \%$ due to secondary re-ascent of the testis. This is to be compared with about 95\% anatomical efficacy of primary orchiopexy (Fig. 1).
Animal experiments have shown that after a single large dose of hCG, the intra-testicular pressure increases, and interstitial oedema and extravasation of leukocytes are seen (14-16). Such inflammation-like morphological changes have also been shown in biopsies obtained at surgery performed at the end of (unsuccessful) hCG treatment (17), but these changes disappear later on. However, more recent studies show that immediately after hCG, there is an increased apoptosis of germ cells in hCG-treated testes, compared with those that went directly to surgical treatment (18, 19). Furthermore, when these boys were followed-up into adulthood, it was found that the hCG-treated testes were $50 \%$ smaller, and that there was an inverse relationship between the degree of apoptosis at the end of hCG treatment and testicular volume in adulthood. Further similar studies should be carried out before drawing final conclusions. However, with the information available to date, we must assume that the hCG treatment may damage future spermatogenesis.

When considering the poor efficacy of hormonal treatment and its possible adverse effects on spermatogenesis, the consensus group concluded that surgery is generally to be preferred.

\section{When should the UDT be treated?}

This has also been a matter of controversy. The key issue is whether the testis is irreversibly damaged if left in a warmer than normal environment or whether it can recover fully once it is brought into the scrotum. And if recovery is possible, does the extent of recovery depend on the time spent above the scrotum? Again, until recently, randomized controlled studies have been lacking.

At birth, 3-8\% of all boys demonstrate uni- or bilateral UDT (1), but most of these retained testes

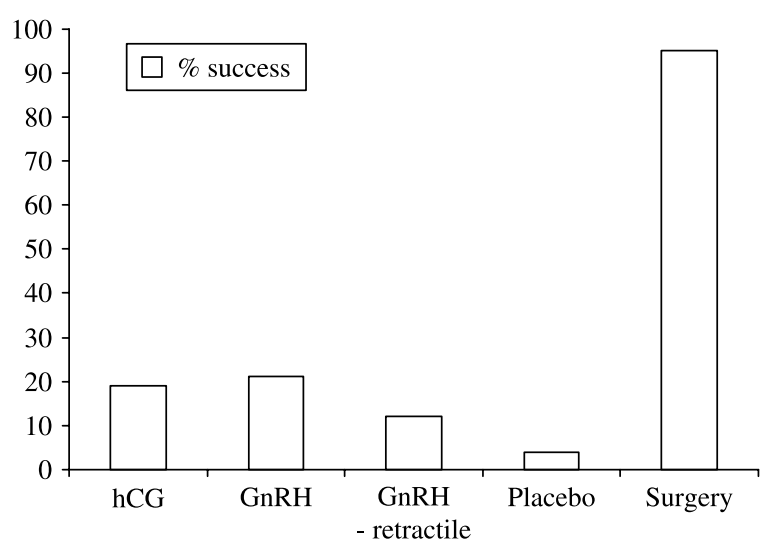

Figure 1 Percent retained testes that descend into scrotum after treatment with human chorionic gonadotropin (hCG), gonadotropin-releasing hormone $(\mathrm{GnRH}), \mathrm{GnRH}$ after excluding retractile testes (GnRH-retractile), placebo and surgery. Meta-analysis of nine randomised controlled studies, compared with surgery. Data from (11). 
descend into the scrotum during the first 3 months. Thus, there is presently consensus that the diagnosis should not be finally established before 6 months of age. Over the last decade, recommendations by professional societies have gradually decreased the recommended age for surgery. Thus, in 1986, the American Academy of Pediatrics recommended surgery at 4-6 years of age; in 1996, it was lowered to 1 year. The latter recommendation was based on findings that the number of germ cells per seminiferous tubule in retained testes start to deviate from normal at 1-2 years of age $(20,21)$.

The first results from a randomized controlled study, comparing the testicular growth after surgery at 9 months or 3 years of age, were recently published $(22,23)$. Orchiopexy at 9 months was followed by a partial catch-up growth, which was not seen after the late surgery. This suggests that the testis at least partly loses its capacity for recovery if left in the scrotum beyond 1 year of age. Early surgery therefore seems more advantageous. So far, randomized studies designed to identify the precise optimal time for surgery before 3 years of age are needed. Judging from the publications available to date, surgery before 1 year of age was recommended by the consensus group.

A recent publication argues that surgery for acquired UDT could wait until early puberty (24). These authors base their conclusions on the finding that if surgery is postponed until puberty, many retained testicles will have descended spontaneously. However, these authors consider the anatomical position only, not the spermatogenic function in adult life, which is the primary aim for treatment.

The consensus group unanimously recommended surgery between 6 and 12 months of age, or soon after diagnosis, if that is made later in life.

\section{Where, and by whom, should UDT be treated?}

In skilled hands, complications from orchiopexy are not greater if done before 1 year of age than if done after. This holds true also for general anaesthesia. However, surgery of infants needs the facilities of a unit with personnel trained both in surgery and anaesthesia of infants. In most countries, this means that it should be done at centres for paediatric surgery or urology. These recommendations by the consensus group will call for some degree of centralization or surgery.

\section{Conclusions of the consensus group}

After diagnosis of congenital cryptorchidism in a newborn boy, he should be referred to a paediatric surgeon/urologist no later than at 6 months of age. If the testis by then has descended into the scrotum, or if it is classified as

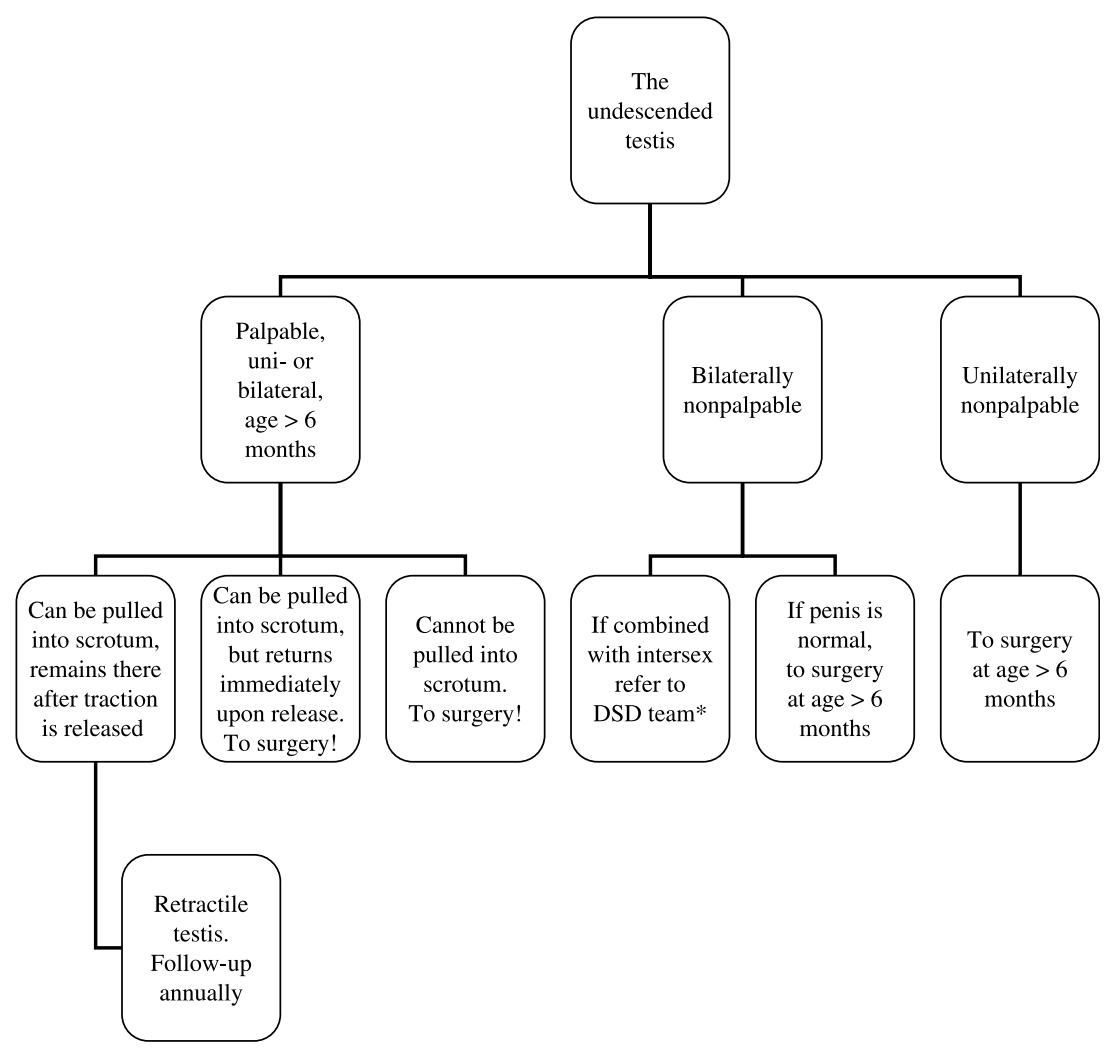

Figure 2 Schematic representation of a decision tree that can be used for management of boys with undescended testes. From (2), with permission. *A DSD (Disorder of Sexual Development) team should include experts with experience of management of children born with undetermined sex, from areas including endocrinology, urology, gynaecology, medical genetics and child psychiatry 
'retractile', the parents should be advised that annual follow-up will be needed throughout childhood, since there is a very significant risk for re-ascent. If the testis is not descended by 6 months of age, the paediatric surgeon/urologist should schedule orchiopexy before 1 year of age. If a testis is found to be undescended at any age after 6 months, the patient should be referred for surgery, to paediatric surgeons/urologists if the boy is less than 1 year old, if he has bilateral or non-palpable testes, or if he has got relapse of cryptorchidism. Unilateral cases less than 1 year old may also be operated by other competent surgeons. A suggested flowsheet is shown in Fig. 2.

\section{Acknowledgements}

The following scientists co-authored the consensus document: E Martin Ritzén, A Bergh, R Bjerknes, P Christiansen, S Haugen, N Jörgensen, C Kollin, S Lindahl, G Läckgren, KM Main, A Nordenskjöld, E Rajpert-De Meyts, O Söder, S Taskinen, A Thorsson, J Thorup and J Toppari.

\section{Disclosure}

This paper forms part of a European Journal of Endocrinology supplement, supported by Ferring pharmaceuticals. The author discloses: no potential conflicting relationship with Ferring. This article was subject to rigorous peer review before acceptance and publication.

\section{References}

1 Virtanen Helena E, Bjerknes Robert, Cortes Dina, Jørgensen Niels, Rajpert-De Meyts Ewa, Thorsson Arni V, Thorup Jørgen \& Main Katharina M. Cryptorchidism: classification, prevalence and long-term consequences. Acta Paediatrica 2007 96 611-616.

2 Ritzén EM, Bergh A, Bjerknes R, Christiansen P, Cortes D, Haugen SE, Jörgensen N, Kollin C, Lindahl S, Läckgren G, Main KM, Nordenskjöld A, Rajpert-De Meyts E, Söder O, Taskinen S, Thorsson A, Thorup J, Toppari J \& Virtanen H. Nordic consensus on treatment of undescended testes. Acta Paediatrica 200796 638-643.

3 Bergh A \& Söder O. Studies of cryptorchidism in experimental animal models. Acta Paediatrica 200796 617-621.

4 Virtanen HE, Cortes D, Rajpert-De Meyts E, Ritzén EM, Nordenskjöld A, Skakkebaek NE \& Toppari J. Development and descent of the testis in relation to cryptorchidism. Acta Paediatrica 200796 622-627.

5 Thorsson AV, Christiansen P \& Ritzén M. Efficacy and safety of hormonal treatment of cryptorchidism: current state of the art. Acta Paediatrica 200796 628-630.

6 Thorup J, Haugen S, Kollin C, Lindahl S, Läckgren G, Nordenskjold A \& Taskinen S. Surgical treatment of undescended testes. Acta Paediatrica 200796 631-637.

7 Lee PA \& Coughlin MT. Fertility after bilateral cryptorchidism. Evaluation by paternity, hormone, and semen data. Hormone Research $20015528-32$.

8 Lee PA \& Coughlin MT. The single testis: paternity after presentation as unilateral cryptorchidism. Journal of Urology 2002168 1680-1682.
9 Miller KD, Coughlin MT \& Lee PA. Fertility after unilateral cryptorchidism. Paternity, time to conception, pretreatment testicular location and size, hormone and sperm parameters. Hormone Research 200155 249-253.

10 Pettersson A, Richiardi L, Nordenskjold A, Kaijser M \& Akre O. Age at surgery for undescended testis and risk of testicular cancer. New England Journal of Medicine 2007356 1835-1841.

11 Pyorala S, Huttunen NP \& Uhari M. A review and meta-analysis of hormonal treatment of cryptorchidism. Journal of Clinical Endocrinology and Metabolism 199580 2795-2799.

12 Henna MR, Del Nero RG, Sampaio CZ, Atallah AN, Schettini ST, Castro AA \& Soares BG. Hormonal cryptorchidism therapy: systematic review with metanalysis of randomized clinical trials. Pediatric Surgery International 200420 357-359.

13 Ong C, Hasthorpe S \& Hutson JM. Germ cell development in the descended and cryptorchid testis and the effects of hormonal manipulation. Pediatric Surgery International 200521 240-254.

14 Hjertkvist M, Bergh A \& Damber JE. HCG treatment increases intratesticular pressure in abdominal testes in unilaterally cryptorchid rats. Journal of Andrology 19889 116-120.

15 Bergh A, Rooth P, Widmark A \& Damber JE. Treatment of rats with hCG induces inflammation-like changes in the testicular microcirculation. Journal of Reproduction and Fertility 198779 135-143.

16 Assmus M, Svechnikov K, von Euler M, Setchel B, Sultana T, Zetterström C, Holst M, Kiess W \& Söder O. Single subcutaneous administration of chorionic gonadotropin to rats induces a rapid and transient increase in testicular expression of pro-inflammatory cytokines. Pediatric Research 200557 896-901.

17 Hjertkvist M, Läckgren G, Plöen L \& Berg A. Does hCG treatment induce inflammation-like changes in undescended testes in boys? Journal of Pediatrics 1993103 892-897.

18 Heiskanen P, Billig H, Toppari J, Kaleva M, Arsalo A, Ropala J \& Dunkel L. Apoptotic cell death in the normal and cryptorchid human testis: the effect of human chorionic gonadotropin on testicular cell survival. Pediatric Research Surgery 199628 254-258.

19 Dunkel L, Taskinen S, Hovatta O, Tilly JL \& Wikstrom S. Germ cell apoptosis after treatment of cryptorchidism with human chorionic gonadotropin is associated with impaired reproductive function in the adult. Journal of Clinical Investigation 1997100 2341-2346.

20 Mengel W, Hienz A, Sippel WG \& Hecker WCH. Studies on cryptorchidism: a comparison of histological findings in the germinative epithelium before and after the second year of life. Journal of Pediatric Surgery 1974 9 445-450.

21 Hadziselimovic F, Herzog B \& Seguchi H. Surgical correction of cryptorchidism at 2 years: electron microscopic and morphometric investigation. Journal of Pediatric Surgery 197510 19-26.

22 Kollin C, Hesser U, Ritzén EM \& Karpe B. Testicular growth from birth to two years of age, and the effect of orchidopexy at age nine months: a randomized, controlled study. Acta Paediatrica 200695 318-324.

23 Kollin C, Karpe B, Hesser U, Granholm T \& Ritzén EM. Surgical treatment of unilaterally undescended testes: testicular growth after randomization to orchiopexy at age 9 months or 3 years. Journal of Urology $2007 \mathbf{1 7 8} 1589-1593$.

24 Hack WW, van der Voort-Doedens LM, Sijstermans K, Meijer RW \& Pierik FH. Reduction in the number of orchidopexies for cryptorchidism after recognition of acquired undescended testis and implementation of expectative policy. Acta Paediatrica 2007 $96915-918$.

Received 11 August 2008

Accepted 22 August 2008 